CLINICAL STUDY

\title{
Impact of protein energy malnutrition on thyroid size in an iodine deficient population of Gujarat (India): is it an aetiological factor for goiter?
}

\author{
Sheela R Brahmbhatt, Rajesh M Brahmbhatt and Steven C Boyages \\ Department of Diabetes and Endocrinology, Westmead Hospital, Westmead, NSW 2145, Australia \\ (Correspondence should be addressed to S R Brahmbhatt, Department of Diabetes and Endocrinology, Westmead Hospital, Westmead, NSW 2145, \\ Australia; Email: sheelab@westgate.wh.usyd.edu.au) \\ (Requests for offprints should be addressed to S C Boyages, Department of Diabetes and Endocrinology, Westmead Hospital, Westmead, \\ NSW 2145, Australia)
}

\begin{abstract}
Objective: To assess the severity of protein energy malnutrition (PEM) in iodine deficient subjects and to assess the impact of PEM on thyroid size.

Methods: 1002 subjects (530 school-aged children and 472 adults) were assessed for PEM by direct anthropometric measurements of height, weight, triceps skinfold (TSF) thickness, mid upper arm circumference (MUAC) and thigh circumference (TC), and derived indices of body surface area (BSA), body mass index (BMI), and Z-scores for weight-for-age (WAZ), height-for-age (HAZ), and weight-forheight (WHZ). Severity of PEM was based on the World Health Organization (WHO) criteria and the threshold on the Waterlow classification. Thyroid size was measured by ultrasonography to determine the thyroid volume (TV). Linear regression analysis was performed between TV and anthropometric parameters.

Results: Children had severe PEM as evident from the WHO percentage prevalence of stunting $(\mathrm{HAZ}<-2 \mathrm{SD})=64 \%$ (where $<-2 \mathrm{SD}$ is the Z-score deficit), wasting (WHZ $<-2 \mathrm{SD})=43 \%$, underweight $(\mathrm{WAZ}<-2 \mathrm{SD})=82 \%$ and $\mathrm{BMI}<16 \mathrm{~kg} / \mathrm{m}^{2}=90 \%$. Waterlow classification showed that children were either stunted or wasted, or stunted and wasted, or stunted and obese. Nearly $100 \%$ (529/530) of the children had goiter as evidenced from enlarged TV-for-BSA when compared with the WHO reference. There was a weak but statistically significant $(P<0.05)$ positive correlation between TV and BSA, weight, height, MUAC, TC and HAZ but a negative correlation between TV and WHZ, BMI and TSF $(r=-0.1-0.2)$.

Adults had PEM as evident from BMI $<18.5 \mathrm{~kg} / \mathrm{m}^{2}$ in $54 \%$ subjects. Median MUAC $=22.7 \mathrm{~cm}$ reveals prolonged severe PEM. Eighty-two percent had enlarged TV $(>20 \mathrm{ml})$. There was a significant $(P=0.01)$ negative correlation between TV and MUAC.

Conclusions: (i) The severity of acute (wasting) and chronic (stunting) PEM is very high in Gujarati children. They are stunted or wasted, or stunted and wasted, or stunted and obese. Gujarati adults are thin with low protein and fat reserves. (ii) Anthropometric parameters showed a significant $(P<0.001)$ correlation $(r=0.1-0.2)$ with thyroid size. (iii) Higher prevalence of goiter may be due to macro-nutrient malnutrition (PEM) in the face of micro-nutrient malnutrition (iodine deficiency disorders, IDD).
\end{abstract}

European Journal of Endocrinology 145 11-17

\section{Introduction}

The possibility that factors other than iodine deficiency contribute to the production of endemic goiter was perceived as early as 1924 (1). Of the world's undernourished people more than half live in India. Because of the high cost of animal protein and constraints imposed by caste and religious norms, most Indians are vegetarians and depend greatly on pulses. The commonly encountered nutritional disorders are protein energy malnutrition (PEM), and vitamin A, iron and iodine deficiencies (IDD). Although IDD is a specific nutritional disorder due to deficiency of the micronutrient iodine, the effects of generalized PEM on the expression and severity of IDD, in particular goiter, remains to be elucidated (2).

We have previously reported that in Gujarat (Western India) mild to moderate IDD persists (median urinary iodine $56 \mu \mathrm{g} / \mathrm{l}$ ), but the prevalence of goiter $(100 \%)$ was greater than expected for the degree of 
Table 1 Classification for assessing severity of malnutrition by percentage prevalence ranges of three indicators among children under 5 years of age.

\begin{tabular}{llcccc}
\hline Z-score $<-2$ SD & Indicator & Low & Medium & High & $\begin{array}{l}\text { Very } \\
\text { high }\end{array}$ \\
\hline Height-for-age & Stunting & $<20$ & $20-29$ & $30-39$ & $\geq 40$ \\
Weight-for-age & Underweight & $<10$ & $10-19$ & $20-29$ & $\geq 30$ \\
Weight-for-height & Wasting & $<5$ & $5-9$ & $10-14$ & $\geq 15$ \\
\cline { 5 - 6 } & & & & &
\end{tabular}

Data taken from (6).

iodine deficiency (3). We found that almost all children were goitrous by using ultrasonography and speculated that other factors such as concomitant goitrogen intake or the effects of PEM as evidenced from low body mass index (BMI) might be significant contributors to the greater than expected prevalence of goiter in this population (3). If PEM was a significant factor then apart from its effects on increasing thyroid size, it would further compromise thyroid hormone homeostasis.

The principle aim of the present study was to determine the relative contribution of PEM as determined by direct and derived anthropometric indices on thyroid size in the mild to moderate iodine deficient school-aged children and adult population of Gujarat, India.

\section{Subjects and methods}

A total of 1002 subjects having mild to moderate iodine deficiency (based on determination of urinary iodine in all subjects) were included in the study. The characteristics of these subjects, methods of selection and geography of the endemia have been reported previously $(3,4)$.
There were 530 children aged 6-15 years and 472 adults aged 16-83 years from the Baroda and Dang districts of Gujarat State. The detailed results of their iodine status as indicated by outcome indicators (clinical and biochemical), age, sex, geographical distribution and data on diet have been reported elsewhere $(3,4)$. Serum thyroxine levels were not measured in our subjects due to their poor sensitivity, but blood spot thyrotropin (TSH) was measured in all subjects $(3,4)$. A thorough clinical examination was carried out to discover stigmata of malnutrition such as xeropthalmia, Bitot's spots and skin changes and these were recorded. PEM was assessed by direct anthropometric measurements of height, weight, mid upper arm circumference (MUAC), thigh circumference (TC) and triceps skinfold (TSF) thickness and derived indices like body surface area (BSA), body mass index (BMI), arm muscle area (AMA) and arm fat area (AFA). AMA measures lean body mass whereas AFA reflects the subcutaneous adipose tissue.

\section{World Health Organization (WHO) classification for PEM}

Z-score deficits $(<-2 \mathrm{SD})$ were calculated for height-forage (HAZ), weight-for-age (WAZ) and weight-for-height (WHZ) for all children (5). These deficits give rise to three indicators of PEM, stunting, underweight and wasting respectively, that classify the severity of PEM by the percentage prevalence ranges (6) (Table 1). Wasting is the preferred indicator for thinness in children. These reference ranges, however, are only for children less than 5 years of age (6).

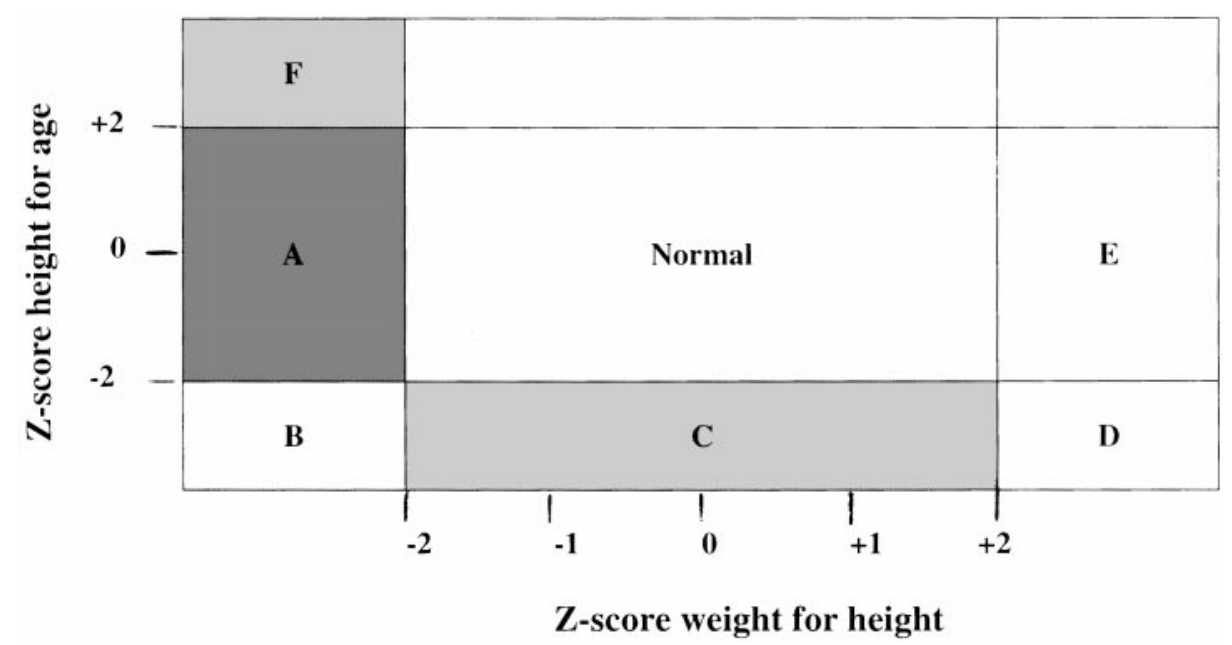

Figure 1 Waterlow classification. A, C, D and F: stunted or wasted. B: stunted and wasted. E: obese. Wasting: lean condition due to acute nutritional problems. Stunting: reduced linear growth due to chronic nutritional problems. 
Waterlow classification (combination of HAZ and WHZ indices)

This classification combines each of the derived indices as a global plot to determine the relative distribution of normal and abnormal anthropometry (Fig. 1) (7). Thus the Waterlow classification presents an overview of the thresholds of malnutrition in a population and divides them into one of six groups (A to $\mathrm{F}$ ) as shown in the legend for Fig. 1.

\section{Thyroid volumes (TV)}

In schoolchildren the thyroid glands were classified as 'normal' or 'enlarged' using the 97th percentile of the WHO reference values as cut off (8). In adults, $\mathrm{TV}>20 \mathrm{ml}$ was considered as enlarged (9).

\section{Statistical methods}

Proportion, mean, standard deviation and median (with interquartile range) have been used to describe the data, as appropriate. Statistical analysis was performed using SPSS version 6.1.2. Thyroid volume was logarithmically transformed and the KolmogorovSmirnov test was used to verify normality of the transformed data. Differences in thyroid volume and other nutritional parameters between districts were tested using the Mann-Whitney test. $t$-tests were used to test for gender differences in anthropometric and clinical parameters. Linear regression analysis was used to test for association between thyroid volume and PEM variables. The Bonferroni method was used to correct the significance levels for multiple comparisons.

\section{Results}

Subjects (adults and children) had no clinical signs of vitamin A deficiency. However as previously reported they were mild to moderately iodine deficient $(3,4)$.

\section{Prevalence of PEM and goiter}

Children PEM as assessed by the three indicators of stunting, wasting and underweight was highly prevalent in both the Baroda and Dang districts. Sixty four percent $(339 / 530)$ of children had stunted growth, $57 \%(273 / 481)$ had wasting and $82 \%(434 / 530)$ were underweight.

Eighty percent had BMI values less than $15 \mathrm{~kg} / \mathrm{m}^{2}$ thereby indicating that the total body fat content was less than $5 \%$ of body-weight. As BMI is an important index for thinness in children over 10 years of age, its frequency distribution as shown in Fig. 2 is only used

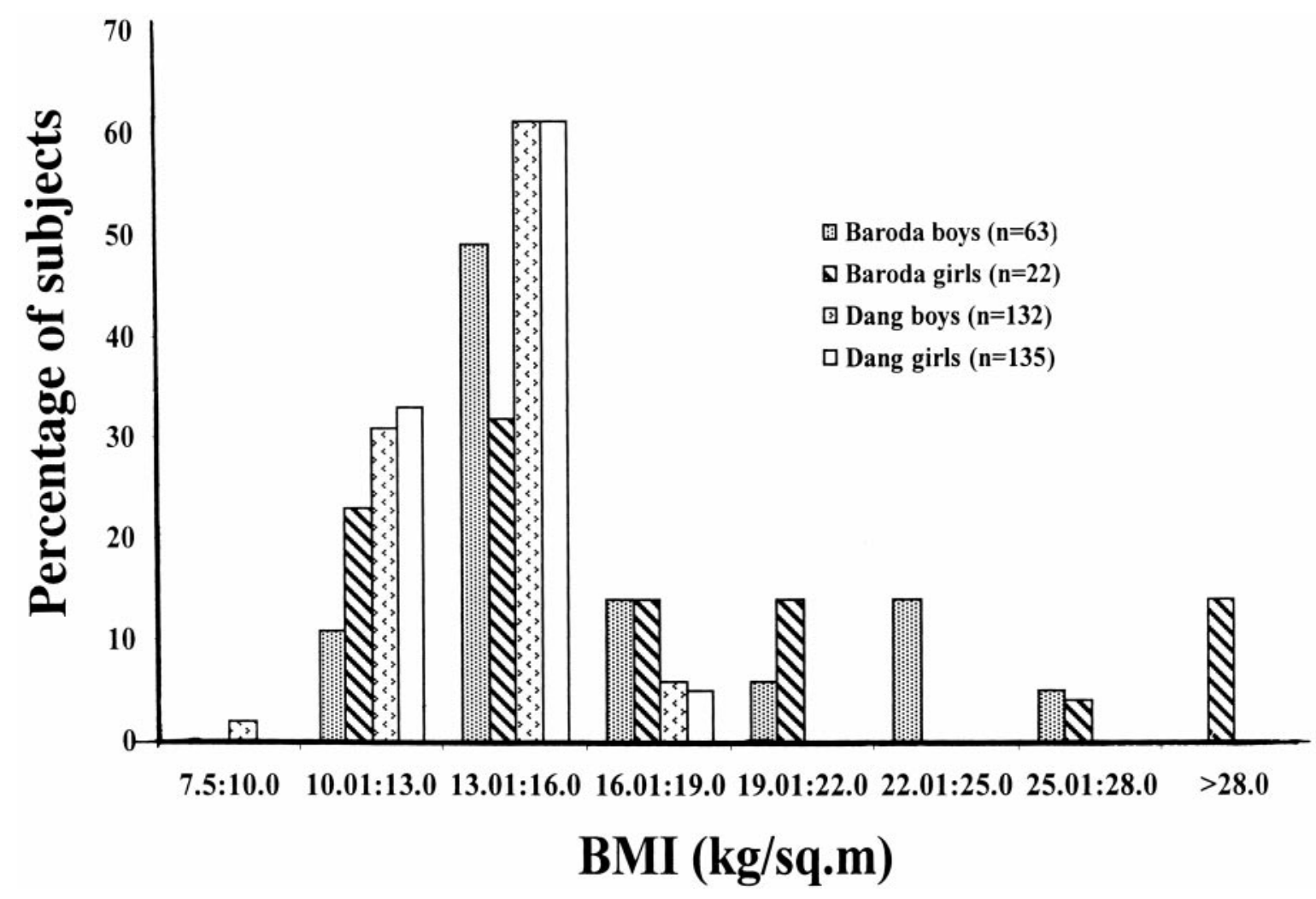

Figure 2 BMI frequency distribution for Gujarati children aged $>10$ to 15 years. 
Table 2 Anthropometric parameters and thyroid volume in children.

\begin{tabular}{|c|c|c|c|c|c|}
\hline Parameter & Mean \pm S.D. & Median (IQR) & Mean \pm S.D. & Median (IQR) & $P$ value \\
\hline Dang $(n=412)$ & \multicolumn{2}{|c|}{ Girls $(n=219)$} & \multicolumn{2}{|c|}{ Boys $(n=193)$} & \\
\hline WAZ & $-2.4 \pm 0.6$ & $-2.5(-2.8:-2.1)$ & $-2.4 \pm 0.6$ & $-2.5(-2.8:-2)$ & 0.48 \\
\hline HAZ & $-2.3 \pm 1$ & $-2.4(-2.8:-1.6)$ & $-2.1 \pm 1$ & $-2.3(-2.7:-1.5)$ & 0.15 \\
\hline WHZ & $-1.9 \pm 0.8$ & $-2.0(-2.4:-1.4)$ & $-2 \pm 0.9$ & $-2(-2.5:-1.5)$ & 0.68 \\
\hline $\operatorname{TSF}(\mathrm{mm})^{*}$ & $8 \pm 2$ & $7.5(6.5: 9)$ & $6 \pm 1.7$ & $6(5: 7)$ & 0.0001 \\
\hline $\operatorname{MUAC}(\mathrm{cm})^{*}$ & $16.3 \pm 1.7$ & $16(15: 17)$ & $16.2 \pm 1.5$ & $16(15: 17)$ & 0.52 \\
\hline $\mathrm{TC}(\mathrm{cm})^{*}$ & $30.6 \pm 2.8$ & $30.5(29: 32)$ & $31.5 \pm 3$ & $31.5(30: 33.5)$ & 0.0001 \\
\hline BMI $\left(\mathrm{kg} / \mathrm{m}^{2}\right)^{*}$ & $13.9 \pm 5.4$ & $13.2(12: 14)$ & $13.5 \pm 2.4$ & $13.2(12.6: 14)$ & 0.33 \\
\hline $\mathrm{TV}(\mathrm{ml})$ & $29.7 \pm 12.5$ & $27(23: 34)$ & $32 \pm 10$ & $30(25: 36)$ & 0.01 \\
\hline Baroda $(n=118)$ & \multicolumn{2}{|c|}{ Girls $(n=28)$} & \multicolumn{2}{|c|}{ Boys $(n=90)$} & \\
\hline WAZ & $-2.3 \pm 0.7$ & $-2.3(-2.8:-2.3)$ & $-2.5 \pm 0.7$ & $-2.5(-2.9:-2.2)$ & 0.24 \\
\hline $\mathrm{HAZ}$ & $-3.9 \pm 3$ & $3.4(-5.4:-2.0)$ & $-3.3 \pm 2.2$ & $-2.5(-5:-2)$ & 0.16 \\
\hline WHZ & $-1.4 \pm 4.4$ & $0(-1.2: 2.1)$ & $0.29 \pm 3.4$ & $-0.9(-2.0: 1.7)$ & 0.17 \\
\hline $\operatorname{TSF}(\mathrm{mm})^{*}$ & $9.6 \pm 3.7$ & $9(7: 11)$ & $8.1 \pm 2.9$ & $7(6: 9)$ & 0.02 \\
\hline $\operatorname{MUAC}(\mathrm{cm})^{*}$ & $18.1 \pm 2.9$ & $17(16: 20)$ & $17.1 \pm 2.3$ & $17(16: 18.4)$ & 0.07 \\
\hline $\mathrm{TC}(\mathrm{cm})^{*}$ & $33.3 \pm 6.7$ & $32(30: 36.6)$ & $32.6 \pm 4.5$ & $32(29: 35.5)$ & 0.53 \\
\hline BMI $\left(\mathrm{kg} / \mathrm{m}^{2}\right)^{*}$ & $18.5 \pm 8$ & $16(13: 20)$ & $16.5 \pm 5$ & $14(13: 18.6)$ & 0.13 \\
\hline TV $(\mathrm{ml})$ & $27.1 \pm 10$ & $30.7(19: 34)$ & $25 \pm 13$ & $22(14: 35)$ & 0.41 \\
\hline
\end{tabular}

$P$ value indicates significant gender difference for each parameter; *indicates significant $P$ value $(<0.001)$ for district as mentioned in the text. IQR, Interquartile range.

for children in the age range of 11-15 years. This figure shows that a few children had BMI values greater than $19 \mathrm{~kg} / \mathrm{m}^{2}$. These children were from the Baroda district and were severely stunted $(\mathrm{HAZ}<-2 \mathrm{SD})$ accounting for the high BMI. Using BMI alone may be misleading in these circumstances.

Table 2 shows the detailed results of anthropometric and clinical parameters used to assess nutritional

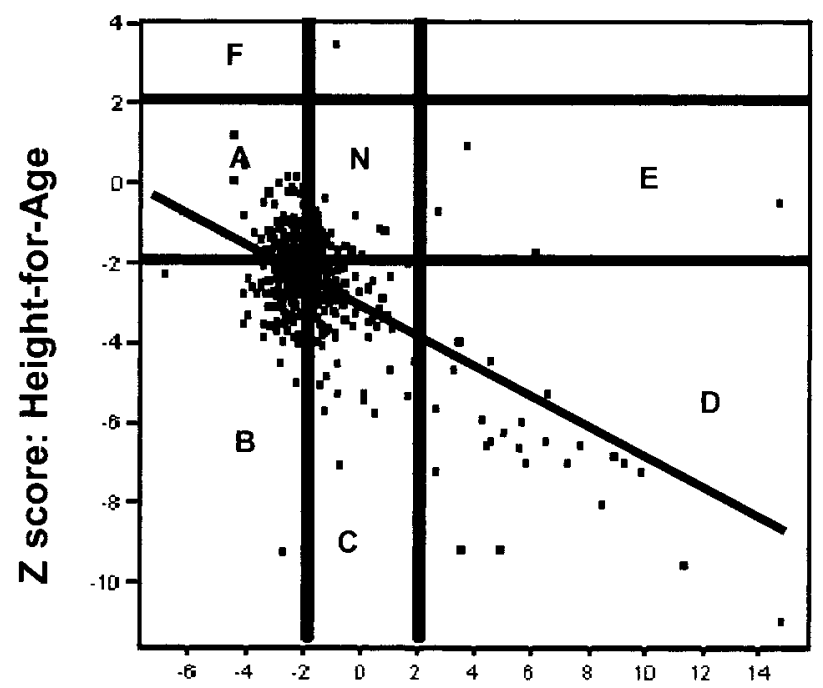

\section{Z score: Weight-for-Height}

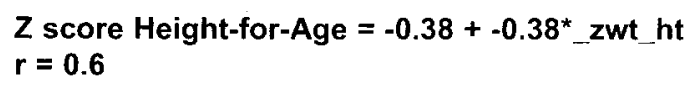

Figure 3 Waterlow classification of studied children. $\mathrm{N}$ : normal. A, C, D and F: stunted or wasted. B: stunted and wasted. E: obese. status and thyroid size. Dang children were more malnourished than Baroda children as evidenced by BMI, weight, height, MUAC, TC and TSF thickness $(P<0.001)$.

The Waterlow classification showed that only a few children were normal and the rest were either stunted or wasted, or both wasted and stunted, or obese and stunted. There was a very strong correlation $(r=0.6)$ between wasting and stunted (Fig. 3).

Goiter by ultrasonography was seen in almost 100\% (529/530) of children compared with the WHO TV-forBSA reference and in 97\% (515/530) of children compared with the WHO TV-for-age reference.

There was no relation of thyroid volume to iodine intake as seen from urinary iodine (UI) on the one hand and different ranges of WHZ on the other hand due to the interplay of multiple factors and goiter in all the children (Table 3). A bimodal relation between thyroid volume and WHZ is evident.

Adults Table 4 shows the detailed results of anthropometric and clinical parameters used to assess nutritional status and thyroid size in adults. Fifty four

Table 3 Thyroid volume $(\mathrm{ml})$ in children according to their iodine excretion and Z-score weight-for-height (WHZ) index.

\begin{tabular}{lcccc}
\hline & \multicolumn{4}{c}{ Urinary iodine $(\mu \mathrm{g} / \mathrm{l})$} \\
\cline { 2 - 5 } WHZ & $<50$ & $51-100$ & $101-300$ & Total \\
\hline$<-3$ & 29.75 & 23.99 & 26.98 & 27.44 \\
-2 to -3 & 28.35 & 29.37 & 29.33 & 28.92 \\
-1 to -2 & 29.19 & 30.68 & 35.97 & 30.96 \\
$>-1$ & 26.65 & 26.15 & 27.8 & 26.85
\end{tabular}


Table 4 Anthropometric parameters and thyroid volume in adults.

\begin{tabular}{|c|c|c|c|c|c|}
\hline & Mean \pm S.D. & Median (IQR) & Mean \pm S.D. & Median (IQR) & $P$ value \\
\hline Dang $(n=80)$ & \multicolumn{2}{|c|}{ Women $(n=55)$} & \multicolumn{2}{|c|}{ Men $(n=25)$} & \\
\hline BMI $\left(\mathrm{kg} / \mathrm{m}^{2}\right)$ & $17.2 \pm 2.7$ & $16(15.6: 18.3)$ & $18 \pm 2$ & $17.9(17: 18.8)$ & 0.17 \\
\hline $\operatorname{BSA}\left(\mathrm{m}^{2}\right)$ & $1.3 \pm 0.1$ & $1.3(1.23: 1.36)$ & $1.46 \pm 0.1$ & $1.45(1.4: 1.5)$ & 0.0001 \\
\hline TSF (mm) & $8.3 \pm 3.0$ & $8.5(6: 10.5)$ & $8.1 \pm 2.9$ & $8(5: 10)$ & 0.76 \\
\hline MUAC $(\mathrm{cm})$ & $21 \pm 1.9$ & $21(20: 22)$ & $23 \pm 2.4$ & $22.5(22: 24)$ & 0.001 \\
\hline $\mathrm{TC}(\mathrm{cm})$ & $38.7 \pm 4.4$ & $39(36: 41)$ & $39.5 \pm 2.9$ & $39.5(37.5: 42)$ & 0.36 \\
\hline $\mathrm{TV}(\mathrm{ml})$ & $50 \pm 25$ & $46(39: 59)$ & $51 \pm 15$ & $47(39: 60)$ & 0.87 \\
\hline Baroda $(n=392)$ & \multicolumn{2}{|c|}{ Women $(n=172)$} & \multicolumn{2}{|c|}{$\operatorname{Men}(n=220)$} & \\
\hline BMI $\left(\mathrm{kg} / \mathrm{m}^{2}\right)$ & $20.3 \pm 4.6$ & $19(17: 22.6)$ & $18.8 \pm 3.4$ & $18(16: 20.7)$ & 0.0001 \\
\hline $\operatorname{BSA}\left(m^{2}\right)$ & $1.4 \pm 0.14$ & $1.4(1.3: 1.5)$ & $1.5 \pm 0.14$ & $1.5(1.4: 1.6)$ & 0.0001 \\
\hline TSF (mm) & $11.7 \pm 4.5$ & $11(9: 14.5)$ & $7.8 \pm 2.9$ & $7(6: 10)$ & 0.0001 \\
\hline MUAC $(\mathrm{cm})$ & $23 \pm 3.5$ & $23(20.5: 25)$ & $23.2 \pm 2.9$ & $23(21.5: 24.5)$ & 0.94 \\
\hline $\mathrm{TC}(\mathrm{cm})$ & $40.7 \pm 6.8$ & $40(36: 45)$ & $40 \pm 5.5$ & $40(36: 43)$ & 0.31 \\
\hline TV (ml) & $33.5 \pm 16$ & $30(21: 42)$ & $35.5 \pm 16$ & $36.4(21: 46)$ & 0.23 \\
\hline
\end{tabular}

$P$ value indicates significant gender difference for each parameter.

IQR, Interquartile range.

percent had PEM (mild to severe) as evidenced by BMI values less than $18.5 \mathrm{~kg} / \mathrm{m}^{2}$. Thus Gujarati adults are thin with low protein and fat reserves as evidenced from their lower MUAC, AMA, AFA and TSF values. Figure 4 shows the frequency distribution of BMI with some overweight subjects found only in the Baroda district (BMI $>25 \mathrm{~kg} / \mathrm{m}^{2}$ ). Enlarged thyroid volume $(>20 \mathrm{ml})$ was found in $388 / 472$ subjects $(82.2 \%)$. More females had goiter (by ultrasound) and more had goiter grade 2 (5 women and 2 men). Thyroid

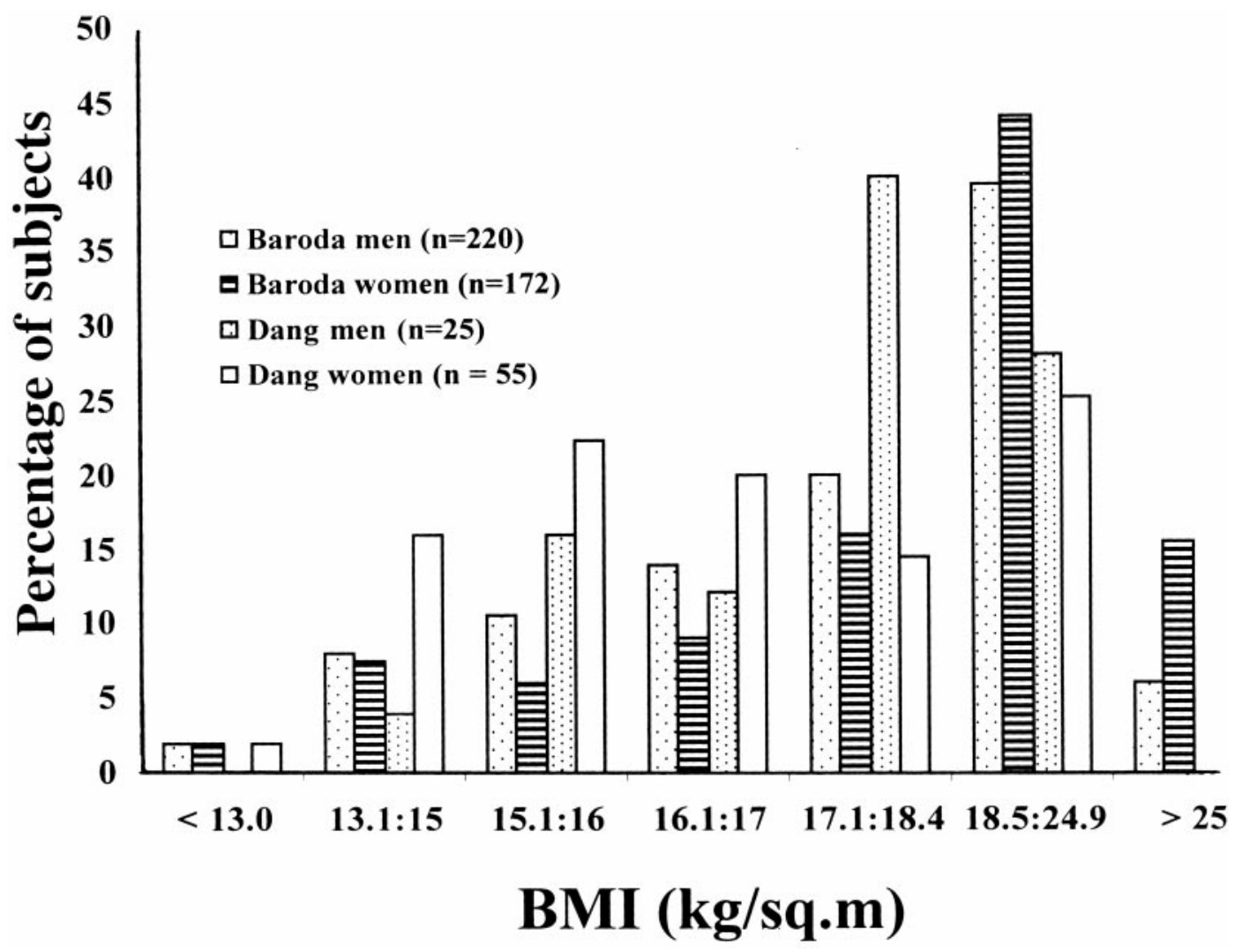

Figure $4 \mathrm{BMI}$ frequency distribution in adults aged $>15$ years from Dang and Baroda districts. BMI range $<15.0=$ very severe malnutrition with total body fat $<5 \%$ of body-weight. BMI range 15.1 to $16.0=$ severe malnutrition. BMI range 16.1 to $17.0=$ moderate malnutrition. BMI range 17.1 to $18.4=$ mild malnutrition. BMI range 18.5 to $24.9=$ normal. 
ultrasound revealed $100 \%$ goiter prevalence in the Dang and $77 \%$ in the Baroda districts. Median thyroid volume was $46.8 \mathrm{ml}$ in Dang and $32.7 \mathrm{ml}$ in Baroda $(P<0.001)$.

\section{Regression analysis}

In children, there was a weak but statistically significant $(P<0.05)$ positive correlation between TV and the variables BSA, weight, height, MUAC, TC, and HAZ (stunting) $(r=0.17,0.11,0.2,0.11,0.14,0.15$ respectively). All these indices are directly or indirectly related to growth in children hence the expected positive correlation.

A weak but statistically significant $(P<0.05)$ negative correlation $(r=-0.14)$ between $\mathrm{TV}$ and the variables TSF and WHZ was seen.

When the logarithmic transformation of TV (LN-TV) was considered, LN-TV showed a weak $(r=-0.11)$ but significant $(P=0.009)$ correlation with BMI. It also showed a significant correlation with HAZ $(r=0.35$, $P=0.0003)$ and WHZ $(r=-0.16, P=0.0003)$.

In adults, there was a weak $(r=-0.1)$ but statistically significant $(P<0.05)$ negative correlation between TV and MUAC as well as AMA, in other words the poorer the protein nutrition the larger the thyroid size. There was no correlation between TV and other anthropometric parameters like weight, height, BMI, BSA and TC. When the logarithmic transformation of TV (LN-TV) was considered, LN-TV showed a weak but statistically significant $(P=0.008)$ correlation with age, TC, MUAC and TSH $(r=-0.20,-0.12,-0.12$, 0.36 respectively).

The best fitting multivariate linear regression models for thyroid volume using backward elimination for children and adults are published elsewhere $(3,4)$.

\section{Discussion}

The present study shows that PEM was highly prevalent in mild to moderately iodine deficient schoolchildren and adults of Gujarat (Western India). Thyroid enlargement was, in part, related to the degree of PEM in children independent of the effect of iodine deficiency (Table 3). Our study thus highlights the complex interplay of nutritional factors that influence the clinical expression of endemic goiter and potentially other iodine deficiency disorders.

The degree of PEM found in this population group by the three indicators stunting, underweight and wasting indicates severe PEM in Gujarat (6). On a population basis, such high levels of stunting have previously been associated with poor socioeconomic conditions and endemic goiter in a rural population (10). This study highlights not only the importance of addressing the fundamental importance of iodine supplementation, but also the importance of addressing nutritional intake in general.
The mechanism of goiter in the setting of PEM is probably multi-factorial. In PEM children, negatively charged iodide is less efficiently absorbed against the electrochemical gradient requiring energy (11). Iodine concentration of the thyroid gland decreases due to depressed iodide clearance and uptake in PEM (12). Thus PEM indirectly results in alterations in iodine metabolism that may lead to thyroid hyperplasia and further reduces circulating thyroid hormone levels. Secondly, PEM may contribute to goitrogenesis directly through the lack of substrate availability, in particular the lack of essential amino acids such as tyrosine (13). These substrate deficiencies are probably exaggerated as subjects consumed a narrow, homogenous vegetarian diet with pulses as the main source of protein. The detection of the amino acid profile in seed proteins has revealed low levels of tyrosine and phenylalanine in the white-coloured seed coat accession compared with the WHO (1991) requirement pattern (14).

Previous studies have shown that the best predictors of thyroid size in normal iodine sufficient children are BSA, weight, height and age whereas WAZ, HAZ and WHZ are less predictive of thyroid volume (15). These authors did not measure other anthropometric parameters of nutrition such as MUAC, TC and TSF. Positive correlation between thyroid weight measured scintigraphically and the ratio of thyroid gland weight to BSA has also been shown (16). The Gujarati children showed the expected positive correlation ( $r=$ $0.12-0.20, P<0.05)$ of thyroid size to variables such as BSA, weight, height and HAZ. The mid upper arm and thigh circumferences in children, but not in adults, were also positively related to thyroid size. The correlation of these growth-determined variables to thyroid volume was less than that found in an iodine sufficient population due to greater thyroid size in the studied population. A stronger positive correlation can be expected in normal iodine sufficient Indian children $(17,18)$.

By contrast, thyroid size was larger in children who exhibited more severe features of PEM. A negative correlation between TV and variables such as BMI, TSF and WHZ (wasting which is the preferred index for thinness in children) was found. These findings were independent of the degree of iodine deficiency, and indicate that PEM is one of the determinants of thyroid size.

Recent studies have shown that nutritional biochemical markers such as thyroxine binding pre albumin (TBPA) show a good relation to WAZ and HAZ scores (19), i.e. TBPA may be a useful marker to assess the effects of nutrition on thyroid size.

Adults also showed a very high prevalence of PEM as evidenced by the prevalence of low BMI (a critical situation) in the population. Almost $54 \%$ of the population had BMI values less than $18.5 \mathrm{~kg} / \mathrm{m}^{2}$ (Fig. 4) (6). There was a negative correlation between TV and MUAC and AMA, indicating a relationship 
between markers of prolonged protein deficiency and thyroid size.

The greatest public health concern of the present findings is the potential impact of PEM not on the development of goiter per se, but the effects on brain development of the fetus and neonate. Although not measured directly, the study findings would support the notion that PEM would further compromise thyroid hormone homeostasis, which would potentiate the impact on fetal and neonatal brain development.

In summary, the present study conducted in subjects with severe PEM in the setting of iodine deficiency has demonstrated that there may be an impact of PEM on thyroid volume as measured by ultrasonography. The study highlights the complex interplay of nutritional factors that determine thyroid size and thus thyroid hormone homeostasis.

\section{Acknowledgements}

We acknowledge the assistance given to us by Professor Creswell Eastman, Director, ICPMR, Western Sydney Area Health Services, Westmead for providing funds for analysis of urinary iodine and blood spot TSH at ICPMR and Karen Byth, Consultant Statistician, Westmead Hospital, Westmead for carrying out the statistical analysis of the data.

\section{References}

1 Geraldo AM. General nutrition and endemic goiter. In Endemic Goiter and Endemic Cretinism, ch 14, pp 269. Eds JB Stanbury \& BS Hetzel. New York: John Wiley \& Sons, 1980.

2 Koutras DA, Christakis G, Trichopoulos D, Dakou-Voutetaki A, Kyriakopoulos V, Fontanares P et al. Endemic goiter in Greece: nutritional status, growth, and skeletal development of goitrous and nongoitrous populations. American Journal of Clinical Nutrition 197326 1360-1368.

3 Brahmbhatt SR, Brahmbhatt RM \& Boyages SC. Thyroid ultrasound is the best prevalence indicator for the assessment of iodine deficiency disorders. European Journal of Endocrinology $200014337-46$.

4 Brahmbhatt SR, Brahmbhatt RM, Eastman CJ \& Boyages SC. Thyroid ultrasonography consistently identifies goiter in adults over the age of 30 years despite a diminished response with aging of the thyroid gland to the effects of goitrogenesis. TheScientificWorld. (In press).

5 World Health Organisation. Data analysis and interpretation. In Measuring Change in Nutritional Status, edn 1, ch 6, pp 19-28. Ed WHO. Geneva: WHO, 1983.
6 World Health Organisation. Physical status: the use and interpretation of anthropometry. Report of a WHO Expert Committee. Technical Report Series 1995 No. 854.

7 Gross R, Kielmann A, Korte R, Schoeneberger H \& Schultink W. Analysis and interpretation of anthropometric indices. In Guidelines for Nutrition Baseline Surveys in Communities, edn 1, ch 4.2, pp 100-103. Jakarta: Published under joint auspices of South East Asian Ministries of Education Organization (SEAMEO), Tropical Medicine and Public Health Network (TROPMED) Central Office and German Agency for Technical Cooperation (GZT) Federal Republic of Germany, 1997.

8 WHO/ICCIDD. Recommended normative values for thyroid volume in children aged 6-15 years. Bulletin of the World Health Organization 199775 95-97.

9 Larsen PR, Davies TF \& Hay ID. Thyroid: anatomy and histology. In Williams Textbook of Endocrinology, edn 9, ch 11, section 3, pp 391. Eds RH William. Philadelphia: Saunders, 1998.

10 Robinson HMP, Betton H \& Jackson AA. Clinical nutrition case. Nutrition Reviews $1986 \mathbf{4 4} 270-273$.

11 Beckers C. Non toxic goiter. In The Thyroid Gland, edn 1, ch 11, pp 238. Eds M De Visscher. Series Ed L Martini. New York: Raven Press, 1980.

12 Gaitan JE, Mayoral LG \& Gaitan E. Defective thyroidal iodine concentration in protein calorie malnutrition. Journal of Clinical Endocrinology and Metabolism 198357 327-333.

13 Polge A, Bancel E, Bellet H, Strubel D, Poirey S, Peray P et al. Plasma amino acid concentrations in elderly patients with protein energy malnutrition. Age and Aging $1997 \mathbf{2 6} 457-462$.

14 Vadivel V \& Janardhanan K. Nutritional and anti-nutritional composition of valvet bean: an under-utilized food legume in South India. International Journal of Food Sciences and Nutrition $200051279-287$.

15 Xu F, Sullivan K, Houston R, Zhao J, May W \& Maberly G. Thyroid volumes in US and Bangladeshi schoolchildren: a comparison with European schoolchildren. European Journal of Endocrinology 1999140 498-504.

16 Orbak Z, Akin Y, Varoglu E \& Tan H. Serum thyroid hormone and thyroid gland weight measurements in protein energy malnutrition. Journal of Pediatric Endocrinology and Metabolism 199811 719-724.

17 Ivarson SA, Persson PH \& Ericsson UB. Thyroid gland volume as measured by ultrasonography in healthy children and adolescents in non-iodine deficient area. Acta Paediatrica Scandinavica 198978 633-634.

18 WHO/UNICEF/ICCIDD. Indicators for assessing IDD and their control through salt iodination. WHO/NUT/94.6. Geneva, WHO, 1994.

19 Malave I, Vethencourt MA, Pirela M \& Cordero R. Serum levels of thyroxine binding prealbumin, C-reactive protein and interleukin- 6 in protein energy undernourished children and normal controls without or with associated clinical infections. Journal of Tropical Pediatrics 199844 256-262.

Received 26 October 2000

Accepted 19 March 2001 